\title{
Nanoprobe Mechanical and Piezoelectric Characterization of ScxAl1-xN(0001) Thin Films
}

Agne Zukauskaite, Esteban Broitman, Per Sandström, Lars Hultman and Jens Birch

\author{
Linköping University Post Print
}

Tweet

N.B.: When citing this work, cite the original article.

Original Publication:

Agne Zukauskaite, Esteban Broitman, Per Sandström, Lars Hultman and Jens Birch, Nanoprobe Mechanical and Piezoelectric Characterization of ScxAl1-xN(0001) Thin Films, 2015, Physica Status Solidi (a) applications and materials science, (212), 3, 666-673.

http://dx.doi.org/10.1002/pssa.201431634

Copyright: Wiley-VCH Verlag http://www.wiley-vch.de/publish/en/

Postprint available at: Linköping University Electronic Press

http://urn.kb.se/resolve?urn=urn:nbn:se:liu:diva-103830 


\title{
Nanoprobe mechanical and piezoelectric characterization of $\mathrm{Sc}_{x} \mathrm{Al}_{1-\mathrm{x}} \mathrm{N}(0001)$ thin films
}

\author{
Agnė Žukauskaitè *, Esteban Broitman ${ }^{* \star}$, Per Sandström, Lars Hultman, and Jens Birch \\ Thin Film Physics Division, Department of Physics, Chemistry, and Biology (IFM), Linköping University, SE-581 83 Linköping, \\ Sweden
}

Received ZZZ, revised ZZZ, accepted ZZZ

Published online ZZZ (Dates will be provided by the publisher.)

Keywords electromechanical characterization, scandium aluminum nitride, nanoindentation, piezoelectric thin films, functional coatings.

* Corresponding author: e-mail agne.zukauskaite@liu.se, Phone: +46 13281232, Fax: +46 13137568

** e-mail esteban.broitman@liu.se, Phone: +46 13 285748, Fax: +46 13137568

Nanoindentation with in-situ electrical characterization is used to investigate piezoelectric scandium aluminum nitride $\left(\mathrm{Sc}_{\mathrm{x}} \mathrm{Al}_{1-\mathrm{x}} \mathrm{N}\right)$ thin films with $\mathrm{Sc}$ contents up to $\mathrm{x}=0.3$. The films are prepared by reactive magnetron sputtering using $\mathrm{Al}_{2} \mathrm{O}_{3}$ substrates with TiN seed layers as bottom electrodes at a substrate temperature of $400{ }^{\circ} \mathrm{C}$. X-ray diffraction shows $c$-axis oriented wurtzite $\mathrm{Sc}_{\mathrm{x}} \mathrm{Al}_{1-\mathrm{x}} \mathrm{N}$, where the crystal quality decreases with increasing $\mathrm{x}$. $\mathrm{Pi}$ ezoresponse force microscopy in mapping mode reveals a single piezoelectric polarization phase in all samples. The hardness decreases from $17 \mathrm{GPa}$ in AlN to $11 \mathrm{GPa}$ in
$\mathrm{Sc}_{0.3} \mathrm{Al}_{0.7} \mathrm{~N}$, while reduced elastic modulus decreases from $265 \mathrm{GPa}$ to $224 \mathrm{GPa}$, respectively. Both direct and converse piezoelectric measurements are demonstrated by first applying the load and generating the voltage and later by applying the voltage and measuring film displacement using a conductive boron doped diamond nanoindenter tip. The $\mathrm{Sc}_{0.2} \mathrm{Al}_{0.8} \mathrm{~N}$ films exhibit an increase in generated voltage in comparison to AlN and a correspondingly larger displacement upon applied voltage, comparable to results obtained by double beam interferometry and piezoresponse force microscopy.
1 Introduction AlN has the highest reported piezoelectric coefficient $d_{33}=5 \mathrm{pm} \mathrm{V}^{-1}$ amongst group IIIA nitrides. It is used in thin film bulk acoustic wave resonator (TFBAR) structures in the telecommunication industry [1]. Recent reports show as much as $400 \%$ increase in piezoelectric response when alloying AlN with Sc to create wurtzite $\mathrm{Sc}_{\mathrm{x}} \mathrm{Al}_{1-\mathrm{x}} \mathrm{N}$ with up to $\mathrm{x}=0.43$ [2-4]. Ab initio calculations explain this to be an intrinsic alloying effect, caused by flattening of the energy landscape along the $c$-axis due to the existence of an unstable hexagonal $\mathrm{ScN}$ phase, when the piezoelectric constant $e_{33}$ increases with a simultaneous decrease in the stiffness constant $c^{E_{33}}$ [5]. Due to competition between the most stable phases - wurtzite AlN and rocksalt $\mathrm{ScN}-$ the resulting films are metastable. However, based on mixing enthalpy calculations, wurtzite is the favored structure below $\mathrm{x}=0.55$ [6]. Additionally to piezoelectric properties, mechanical properties of AlN and $\mathrm{Sc}_{\mathrm{x}-}$ $\mathrm{Al}_{1-\mathrm{x}} \mathrm{N}$ thin films are of interest in microelectromechanical system (MEMS) applications [7]. The knowledge of the mechanical properties is important for understanding the microstructure and morphology of films deposited under different growth conditions as well as during the operation of sensors or other thin film-based devices in applications, where the film could be exposed to a deliberate or unexpected mechanical stress. High elastic modulus, a typical property of group IIIA semiconductor nitrides, is of interest when high frequency in resonant devices needs to be achieved [8].

Nanoindentation is a technique widely viewed as a standard tool for characterization of mechanical properties, such as hardness and elasticity. However, if the indentation is performed using a conductive indenter tip, in-situ electrical characterization is also possible [9]. Piezoelectric nanoindentation (PNI), a method, where the converse piezoelectric effect is observed when an oscillating voltage is applied and the surface displacement is detected [10] has 
recently been introduced as another nanoindentation-based approach to obtain additional information about the material properties. PNI was thus successfully used for electromechanical characterization of lead zirconate titanate (PZT) and $\mathrm{BaTiO}_{3}$ ceramics [10]. Nanoindentation can also be used to induce the direct piezoelectric effect in the material by applying load to generate piezo-voltage, as it has been shown in the case of PZT nanoislands and $\mathrm{ZnO}$ nanowires [11,12].

Currently, the main techniques used for piezoelectric characterization of thin films are piezoresponse force microscopy (PFM) and double beam interferometry (DBI). However, the interpretation of PFM results is usually quite complex due to the dynamic behavior of the detection system, and the measurement is also sensitive to surface contaminations. The use of DBI is not straightforward due to the need of an advanced sample preparation. On the other hand, both PNI and direct voltage generation during the indentation can be done with existing nanoindentation equipment using a conducting tip, and the only requirement for sample preparation is a bottom electrode under the piezoelectric film.

In this report, we employ a standard nanoindentation setup for mechanical and piezoelectric characterization of $\mathrm{Sc}_{\mathrm{x}} \mathrm{Al}_{1-\mathrm{x}} \mathrm{N}$ thin films. Both direct piezoelectric effect, applying constant load to generate voltage, and converse piezoelectric effect, applying constant DC voltage to induce material displacement ( $d c$ PNI) are demonstrated. Wurtzite $\mathrm{AlN}$ is used as a reference and its piezoelectric response is compared to $\mathrm{Sc}_{\mathrm{x}} \mathrm{Al}_{1-\mathrm{x}} \mathrm{N}$ with $\mathrm{x}=0.1,0.2$, and 0.3 .

2 Experimental details Magnetically unbalanced reactive DC magnetron sputtering was used to deposit 250$500 \mathrm{~nm}$ thick $\mathrm{Sc}_{\mathrm{x}} \mathrm{Al}_{1-\mathrm{x}} \mathrm{N}$ films on $\mathrm{Al}_{2} \mathrm{O}_{3}(0001)$ substrates with previously grown $\mathrm{TiN}(111)$ seed layers serving as bottom electrodes [3]. All growth experiments were performed in a UHV system with a base pressure of $6 \times 10^{-7} \mathrm{~Pa}$. In the case of $\mathrm{Sc}_{\mathrm{x}} \mathrm{Al}_{1-\mathrm{x}} \mathrm{N}$, the substrate temperature $\mathrm{T}_{\mathrm{S}}=400{ }^{\circ} \mathrm{C}$ was used, as previous studies have shown it to provide ScAlN with better dielectric properties $[3,13,14]$. Reference AlN samples were deposited both at $\mathrm{T}_{\mathrm{S}}=400$ and $800{ }^{\circ} \mathrm{C}$. X-ray diffraction (XRD) and transmission electron microscopy (TEM) were used for structural characterization of the films.

The composition of the $\mathrm{Sc}_{\mathrm{x}} \mathrm{Al}_{1-\mathrm{x}} \mathrm{N}$ thin films was determined using time-of-flight elastic recoil detection analysis (ToF-ERDA) with a primary ion beam of $40 \mathrm{MeV}^{127} \mathrm{I}^{9+}$ at the Tandem Laboratory in Uppsala, Sweden. The crystalline quality was evaluated using a Philips $\mathrm{Cu} \mathrm{K} \alpha$ x-ray diffraction (XRD) Bragg-Brentano diffractometer in $\omega / 2 \theta$ mode. The polarization phase homogeneity was assessed by means of piezoresponse force microscopy (PFM). The measurements were performed in contact mode using a Dimension 3100 atomic force microscope with a Nanoscope IVa controller at excitation voltage of $10 \mathrm{~V}$ and $a c$
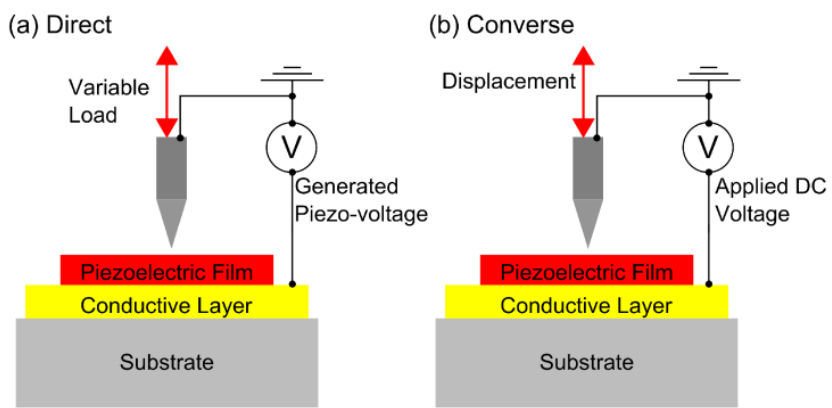

Figure 1 Schematic drawings of the nanoindenter setup for the measurement of (a) direct piezoelectric effect and (b) converse piezoelectric effect.

frequency $5.6 \mathrm{kHz}$. An NSG01 conductive Pt-coated Si tip with a resonance frequency of $f_{\mathrm{r}} \approx 135 \mathrm{kHz}$ was used. The bottom electrode (TiN layer) was in electrical contact with the grounded microscope stage and the voltage was applied through the tip. Instrument calibration using a periodically poled lithium niobate (PPLN) sample was done prior to measuring the $\mathrm{Sc}_{\mathrm{x}} \mathrm{Al}_{1-\mathrm{x}} \mathrm{N}$ samples to ensure a $180^{\circ}$ phase shift between oppositely poled piezoelectric domains.

Characterization of electromechanical and mechanical properties of the films was performed using a Hysitron Triboindenter TI-950. The hardness $H$ and the reduced Young's modulus $E_{\mathrm{r}}$ were measured using a nonconductive Berkovich diamond tip at $1 \mathrm{mN}$ load at a penetration depth below $10 \%$ of the film thickness. To perform electrical measurements a conductive Berkovich borondoped diamond tip with a resistivity of $\sim 3 \Omega-\mathrm{cm}$ was mounted instead. Two different configurations were used to measure the piezoelectric effect, described more in detail previously [11]. In the first configuration (Fig. 1a), the direct piezoelectric effect is detected. Here, nanoindentations under load control with maximum loads $F_{\mathrm{m}}$ ranging from 0.1 to $11 \mathrm{mN}$ are made, while the generated piezoelectric voltage is measured as a function of the applied load and displacement using the nanoscale electrical contact resistance (nanoECR ${ }^{\mathrm{TM}}$ ) configuration of the Triboindenter. This approach is similar to the method suggested by Koval et al. [15] The loading/unloading curve consisted of four parts: during the first $3 \mathrm{~s}$ the probe is in electric contact with the surface with an applied load of $0.002 \mathrm{mN}$; then the force over the probe increases in $1 \mathrm{~s}$ to the maximum value $F_{\mathrm{m}}$; in the third part the load decreases from $F_{\mathrm{m}}$ to $0.002 \mathrm{mN}$, and finally the probe rests above the sample for $3 \mathrm{~s}$ to allow possible relaxation processes to occur. Ten indentations separated by a distance of $50 \mu \mathrm{m}$ were made in each sample. In the second configuration (Fig. 1b) the converse piezoelectric effect is measured; when $40 \mathrm{~V} d c$ bias voltage is applied through the tip, the sample surface displacement is detected. A constant load of $10 \mu \mathrm{N}$ was applied in order to keep the indenter tip in physical contact with the samples. This approach is similar to the method suggested by Rar et al. [10], but in our case the applied voltage is $d c$ instead of $a c$. 




Figure 2 X-ray diffraction patterns of epitaxial $\mathrm{AlN}(0001)$ and $\mathrm{Sc}_{\mathrm{x}} \mathrm{Al}_{1-\mathrm{x}} \mathrm{N}(0001)$ films with a $\mathrm{TiN}(111)$ seed layer on $\mathrm{Al}_{2} \mathrm{O}_{3}(0001)$ substrate.

3 Results and discussion ToF-ERDA measurements showed all $\mathrm{Sc}_{\mathrm{x}} \mathrm{Al}_{1-\mathrm{x}} \mathrm{N}$ samples to be stoichiometric with the $(\mathrm{Al}+\mathrm{Sc}) / \mathrm{N}$ ratio being 1 , and levels of $\mathrm{Sc}$ and $\mathrm{Al}$ constant throughout the film with accuracy of $3 \%$. The composition of the films was determined to be $\mathrm{x}=0,0.1$, 0.2 , and 0.3 . Here $\mathrm{x}$ corresponds to a fraction of $\mathrm{Sc}$ in the total $(\mathrm{Al}+\mathrm{Sc})$.

XRD patterns from $\mathrm{Sc}_{\mathrm{x}} \mathrm{Al}_{1-\mathrm{x}} \mathrm{N}$ films with $\mathrm{x}=0,0.1,0.2$, and 0.3 are shown in Fig. 2. The only observed peaks in the $\theta / 2 \theta$ scans correspond to wurtzite $\mathrm{Sc}_{\mathrm{x}} \mathrm{Al}_{1-\mathrm{x}} \mathrm{N} 0002$ (film), cubic TiN 111 (seed layer), and $\mathrm{Al}_{2} \mathrm{O}_{3} 0006$ (substrate). The $\mathrm{Sc}_{\mathrm{x}} \mathrm{Al}_{1-\mathrm{x}} \mathrm{N}$ peak intensity is decreasing, the peaks broaden, and the peak positions are shifting towards lower angles with increasing Sc concentration. Moreover, according to $\mathrm{Sc}_{\mathrm{x}} \mathrm{Al}_{1-\mathrm{x}} \mathrm{N} 0002$ peak rocking curve measurements (not shown) full width at half maximum (FWHM)

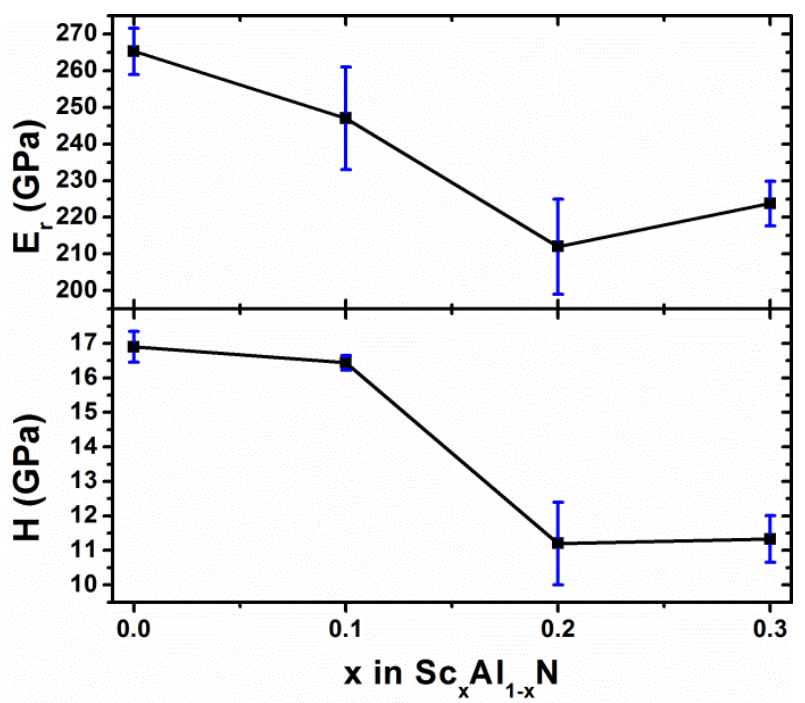

Figure 3 Reduced elastic modulus $\left(E_{\mathrm{r}}\right)$ and hardness $(H)$ of $\mathrm{Sc}_{\mathrm{x}} \mathrm{Al}_{1-\mathrm{x}} \mathrm{N}$ as a function of $\mathrm{Sc}$ concentration. The lines are guides for the eye only.



Figure 4 Piezoresponse force microscopy phase maps for $\mathrm{Sc}_{\mathrm{x}} \mathrm{Al}_{1-\mathrm{x}} \mathrm{N}$ samples with (a) $\mathrm{x}=0$, (b) $\mathrm{x}=0.1$, (c) $\mathrm{x}=0.2$, and (d) $\mathrm{x}=0.3$.

values increase from $0.452^{\circ}$ for pure AlN to above $2^{\circ}$ in samples with $x=0.3$. These results match observations from our previous growth study [3].

Recent theoretical studies show a linear decrease in bulk modulus $B$ for $\mathrm{Sc}_{\mathrm{x}} \mathrm{Al}_{1-\mathrm{x}} \mathrm{N}$ with up to $\mathrm{x}=0.375$ [16] due to the deviation from tetrahedral bonding [5,17], the change in average bond lengths and lattice parameters [6], and the increasing bond ionicity that leads to reduction in shear moduli in tetrahedrally bonded semiconductors [18]. Fig. 3 shows experimentally obtained reduced elastic modulus $E_{\mathrm{r}}$ and hardness $H$ of $\mathrm{Sc}_{\mathrm{x}} \mathrm{Al}_{1-\mathrm{x}} \mathrm{N}$ thin films as a function of Sc concentration. The hardness of AlN found in the literature varies in the range of 12-26 GPa [7,8], and in our case it is $17 \pm 0.45 \mathrm{GPa}$ when $\mathrm{T}_{\mathrm{s}}=800{ }^{\circ} \mathrm{C}$. $\mathrm{H}$ and $\mathrm{E}_{\mathrm{r}}$ obtained during the nanoindentation experiments show a decrease with the addition of Sc from $17 \mathrm{GPa}$ in AlN to $11 \mathrm{GPa}$ in $\mathrm{Sc}_{0.3} \mathrm{Al}_{0.7} \mathrm{~N}$, and from $265 \mathrm{GPa}$ down to $224 \mathrm{GPa}$, respectively. Even if $E_{\mathrm{r}}$ cannot be directly compared to a bulk modulus $B$, the $15.5 \%$ reduction in $E_{\mathrm{r}}$ observed experimentally is close to the $14 \%$ theoretically predicted $B$ reduction in [16]. $E_{\mathrm{r}}$ shows similar trends to experimental and theoretical Young's modulus $E$ in [19] up to x $=0.2$, thus confirming the evolution of the elastic properties of $\mathrm{Sc}_{\mathrm{x}} \mathrm{Al}_{1-\mathrm{x}} \mathrm{N}$ with increasing $\mathrm{x}$.

The results from PFM phase mapping are shown in Fig. 4. Here, the contrast comes from the phase difference between the applied $a c$ signal and the piezoresponse. In the $c$-axis oriented wurtzite $\mathrm{Sc}_{\mathrm{x}} \mathrm{Al}_{1-\mathrm{x}} \mathrm{N}$ the anion-to-cation $(\mathrm{N}$ and $\mathrm{Al} / \mathrm{Sc}$, respectively) spontaneous polarization points along the c-axis. The "upward" N-polarity $\left(0^{\circ}\right.$ phase angle $)$ and "downward" Al-polarity $\left(180^{\circ}\right.$ phase angle) are represented as dark and bright regions, respectively. The maps 


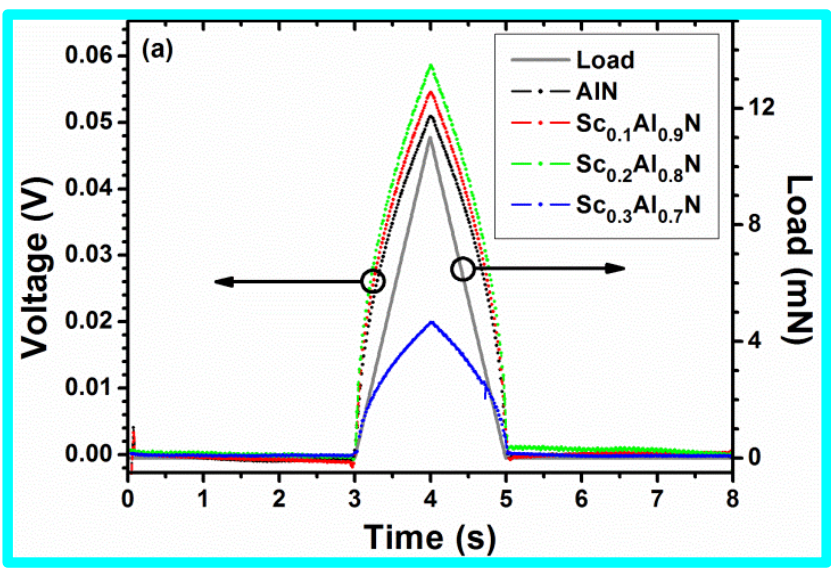

Figure 5 Applied load (solid grey line) and generated voltage (dots) during the direct piezoelectric measurements: (a) triangular loading/unloading profile for $\mathrm{Sc}_{\mathrm{x}} \mathrm{Al}_{1-\mathrm{x}} \mathrm{N}(\mathrm{x}=0,0.1,0.2,0.3)$ at $F_{\mathrm{m}}=11 \mathrm{mN}$, (b) repeatability of the voltage generation (red dots) over multiple loading cycles for $\mathrm{x}=0.1$ at $F_{\mathrm{m}}=5 \mathrm{mN}$, and (c) trapezoidal loading/unloading profile for $\mathrm{Sc}_{\mathrm{x}} \mathrm{Al}_{1-\mathrm{x}} \mathrm{N}(\mathrm{x}=0,0.1)$ at $F_{\mathrm{m}}=5 \mathrm{mN}$.

show that on the $5 \times 5 \mu \mathrm{m}^{2}$ scale all investigated films are uniform and have piezoelectric domains mostly in the "downward" direction. Small inclusions of the opposite polarization are observed, they could be attributed to morphological effects such as local film density variations due to columnar growth, as previously observed in TEM [3]. No trends with respect to the polarization-phase purity as a function of $\mathrm{Sc}$ concentration were found. A quantitative analysis, resulting in piezoelectric coefficients $d_{33}$ of $\mathrm{Sc}_{\mathrm{x}-}$ $\mathrm{Al}_{1-\mathrm{x}} \mathrm{N}$ thin films using the PFM in a similar experimental set-up, has been presented elsewhere [3].

Fig. 5a shows nanoindentation induced voltage response

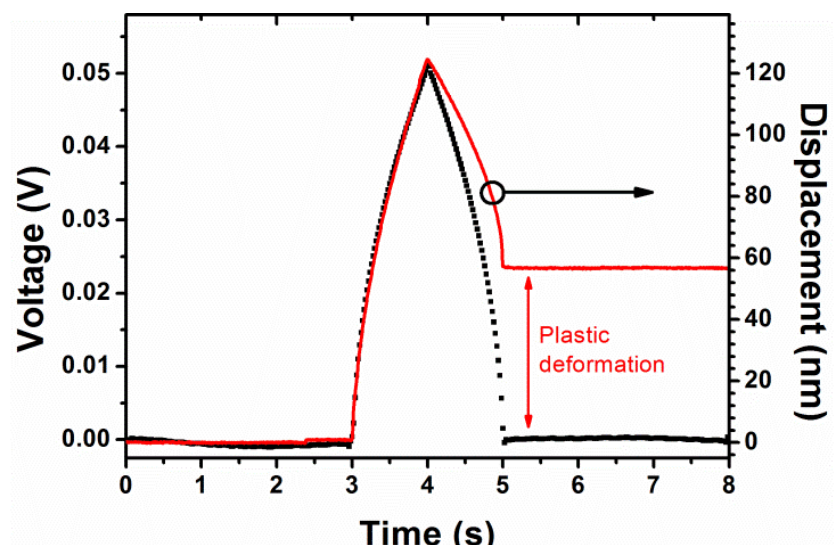

Figure 6 Generated voltage (black dots) and displacement (red line) curves in AlN reference sample.
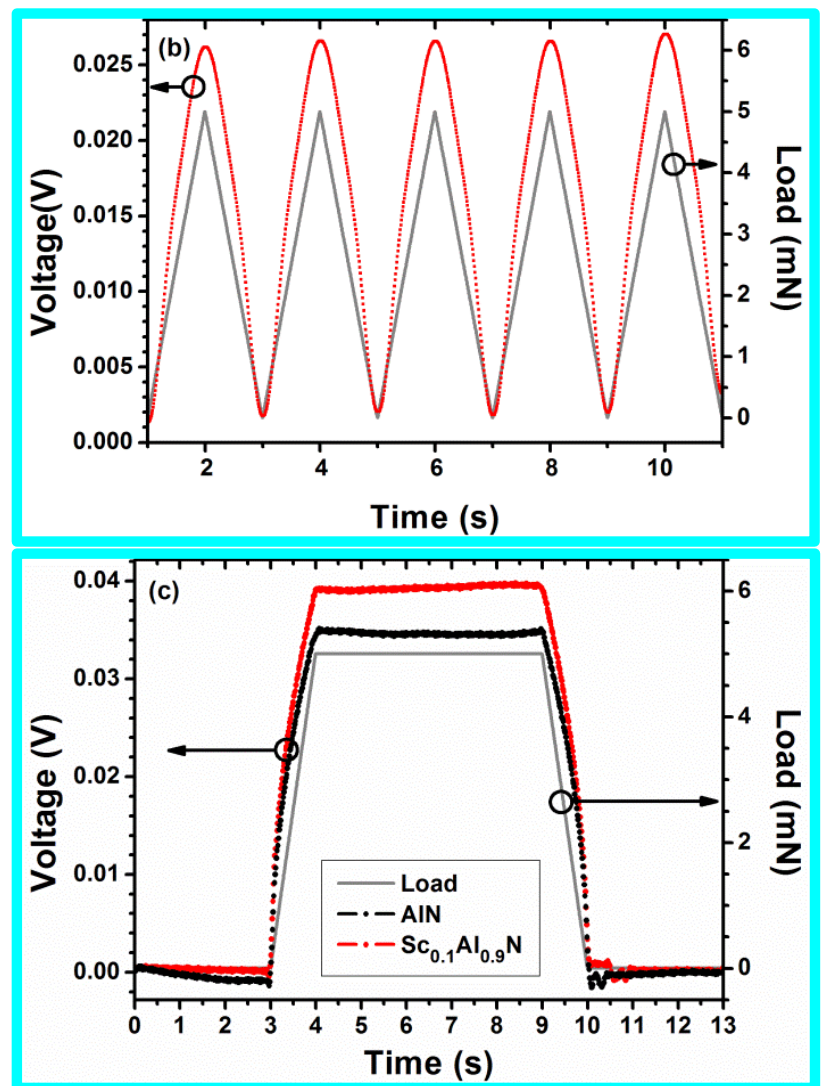

using the direct measurement setup (Fig. 1a), during a triangular loading/unloading. The voltage is shown as a function of time, during which the loading force was increased from $\mathrm{F}=0.002 \mathrm{mN}$ up to $F_{\mathrm{m}}=11 \mathrm{mN}$. The increase in generated voltage was repeatable and it scaled with increased Sc concentration up to $\mathrm{x}=0.2$. Peak voltages of $\mathrm{V}_{\mathrm{p}}=0.051 \mathrm{~V}$, $\mathrm{V}_{\mathrm{p}}=0.054 \mathrm{~V}, 0.059 \mathrm{~V}$, and $0.020 \mathrm{~V}$ were measured for the $\mathrm{AlN}, \mathrm{Sc}_{0.1} \mathrm{Al}_{0.9} \mathrm{~N}, \mathrm{Sc}_{0.2} \mathrm{Al}_{0.8} \mathrm{~N}$, and $\mathrm{Sc}_{0.3} \mathrm{Al}_{0.7} \mathrm{~N}$, respectively. A slight bowing in electrical response during loading and unloading was observed (Fig. 5a). Additional experiments with multiple consecutive load/unload cycles (Fig. 5b) showed the voltage generation to be consistent and repeatable in all investigated samples. Such repeatability suggests that only elastic deformation participates in the voltage generation, as previously shown in [11] and [12]. Moreover, a set of experiments using a trapezoidal loading/unloading profile, where at $F_{\mathrm{m}}=5 \mathrm{mN}$ the load was kept constant for $3 \mathrm{~s}$, was performed to test the stability of the piezoresponse. Examples of such measurements in the AIN and $\mathrm{Sc}_{0.1} \mathrm{Al}_{0.9} \mathrm{~N}$ samples are shown in Fig. $5 \mathrm{c}$, and the response was stable for all investigated samples. While the initial bowing is present here as well, there is almost no change in generated voltage at the peak load over an extended period of time, proving the response to be stable and constant. Similar trends were previously observed during the characterization of PZT nanoislands and $\mathrm{ZnO}$ nanowires [11,12].

From Fig. 3 we can see that both hardness $H$ and elastic modulus $E_{\mathrm{r}}$ of $\mathrm{Sc}_{\mathrm{x}} \mathrm{Al}_{1-\mathrm{x}} \mathrm{N}$ decrease when going from x=0 

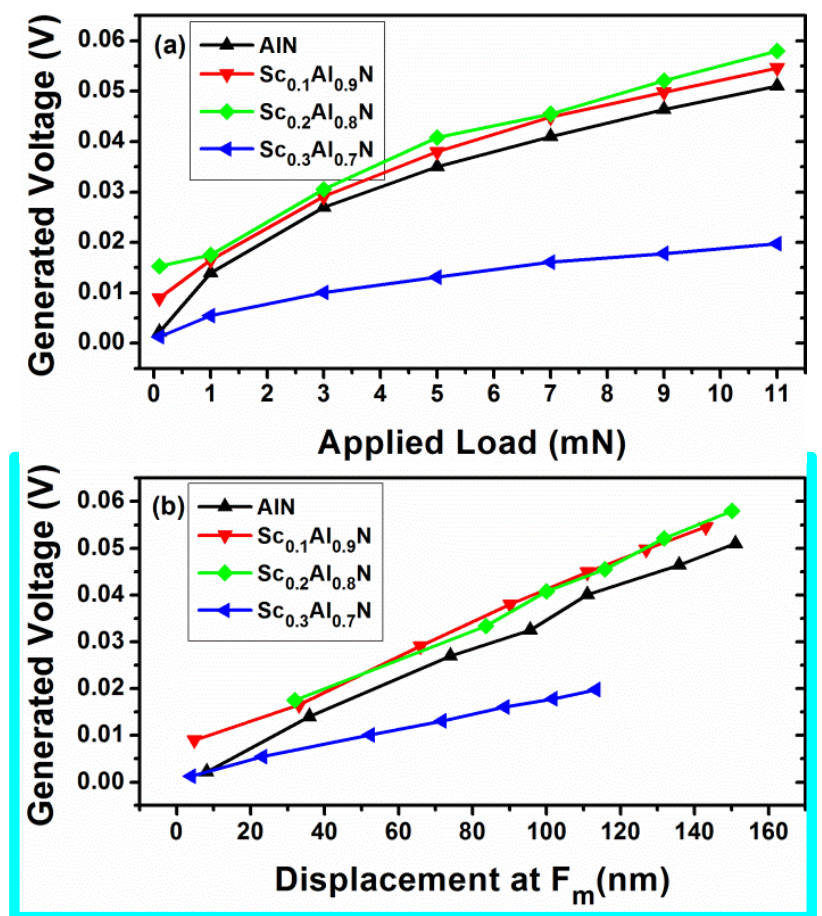

Figure 7 Voltage generated during a direct measurement as a function of (a) applied load (b) displacement at different $F_{\mathrm{m}}$ in $\mathrm{Sc}_{\mathrm{x}} \mathrm{Al}_{1-\mathrm{x}} \mathrm{N}$ samples with $\mathrm{x}=0,0.1,0.2$, and 0.3 . The lines are guides for the eye only.

to $\mathrm{x}=0.3$. This suggests that for the same load $F$ the penetration depth (displacement) will be different, and consequently, the generated piezo-voltage will vary depending on the Sc concentration. Fig. 6 shows the displacement curve together with generated voltage, and during the loading the two curves match very well. However, during the unloading, the displacement in the sample does not return to its initial zero value due to the plastic deformation. A non-linear relationship between the load and the penetration depth is attributed to local structural changes during the nanoindentation process [20,21], which may contribute to the bowing voltage response (Fig. 5a-c) that does not match the linear loading profile. The differences in hardness must therefore be taken into account for quantitative assessment of the piezoelectric properties of materials with different compositions, using the direct piezoelectric effect during nanoindentation.

This is illustrated in Fig. 7, which gives a summary of the results both for the a) generated voltage as a function of load $(0.1-11 \mathrm{mN})$ and $\mathrm{b})$ as a function of the displacement for $\mathrm{x}=0,0.1,0.2$, and 0.3 . In all investigated samples the generated voltage was increasing with the increasing load (Fig. 7a) and it was highest for samples with $\mathrm{x}=0.2$, while samples with $\mathrm{x}=0.3$ show a lower response than the reference AlN. On average, samples with $x=0.1$ showed up to $+10 \%$, and samples with $x=0.2$ has up to $+15 \%$ increase in generated voltage response as compared to the reference AlN sample. When the generated voltage is plotted as a function of displacement (Fig. 7b) the responses from
$\mathrm{Sc}_{0.1} \mathrm{Al}_{0.9} \mathrm{~N}$ and $\mathrm{Sc}_{0.2} \mathrm{Al}_{0.8} \mathrm{~N}$ become very similar, though the generated voltage in both of them is higher than for the AlN samples. These findings show that a quantitative or even a qualitative comparison between samples with different mechanical properties, characterized using the nanoindenter-based techniques, is not straightforward. In both Fig. 7a and Fig. 7b, the lowest generated voltage values were recorded for $\mathrm{Sc}_{0.3} \mathrm{Al}_{0.7} \mathrm{~N}$, in agreement with our previously published data obtained using the DBI and PFM [3], where samples with $\mathrm{x}=0.3$ showed no piezoelectric response independently of growth temperature. The main reason is the degradation of microstructure caused by high Sc concentration. Selected area electron diffraction (SAED) patterns [3] for films with $\mathrm{x}=0.3$ are composed of arc-like spots, in contrast to sharp spots corresponding to c-axis oriented wurtzite structure observed in AlN and samples with up to $\mathrm{x}=0.2$.

As it is evident from Fig. 7, the hardness and the elastic modulus influence the piezoelectric response, as the softer material would be penetrated deeper at the same load, leading to higher generated voltage. A theoretical model of conical indenter in combination with experiments using PZT and $\mathrm{BaTiO}_{3}$ ceramics [22] shows that the analytical predictions based on linear elasticity theory are only applicable before the plastic deformation takes place. The complex strain field, that can be expected to be generated by the anisotropic Berkovich tip in a single crystal specimen, in combination with the large plastic deformation suggest that the piezoelectric coefficients, $e_{33}$, cannot be analytically be determined using common linear elasticity theory from our direct piezoelectric response data using the nanoindenter.

On the other hand, the method of utilizing the converse piezoelectric effect, where a voltage is applied and the displacement is measured by the tip under a very low load, is a much gentler process which does not involve any plastic deformation and induces a minimum of elastic distortion thanks to the $\sim 3$ orders of magnitude lower contact force, as compared to the direct method. Therefore, in order to overcome the hurdles experienced with the direct method, the converse piezoelectric measurements were also performed using the nanoindenter, with the setup shown in Fig. 1b. Upon applying a $+40 \mathrm{~V}$ bias voltage to the conductive Berkovich tip for $5 \mathrm{~s}$, the induced vertical displacement of the films was measured. At lower bias voltage the noise level was too high to obtain accurate and reliable data with our current setup. The results for $\mathrm{AlN}$ and $\mathrm{Sc}_{\mathrm{x}} \mathrm{Al}_{1-}$ ${ }_{x} \mathrm{~N}(\mathrm{x}=0.1,0.2$, and 0.3$)$ are shown in Fig. $8 \mathrm{a}$, where $50 \mathrm{~Hz}$ power-line noise has been filtered out after the measurement using a low-pass filter. The response to the applied $+40 \mathrm{~V}$ was fast and repeatable in all samples, and the displacement increased with Sc concentration for $\mathrm{x}=0.1$ and 0.2 as compared to AlN. However, the piezoelectric response of $\mathrm{Sc}_{0.3} \mathrm{Al}_{0.7} \mathrm{~N}$ was lower than for the other investigated samples, in agreement with our observations during the direct piezoelectric measurement (Fig. 5a). Recent studies show, that piezoelectric properties of AlN depend 

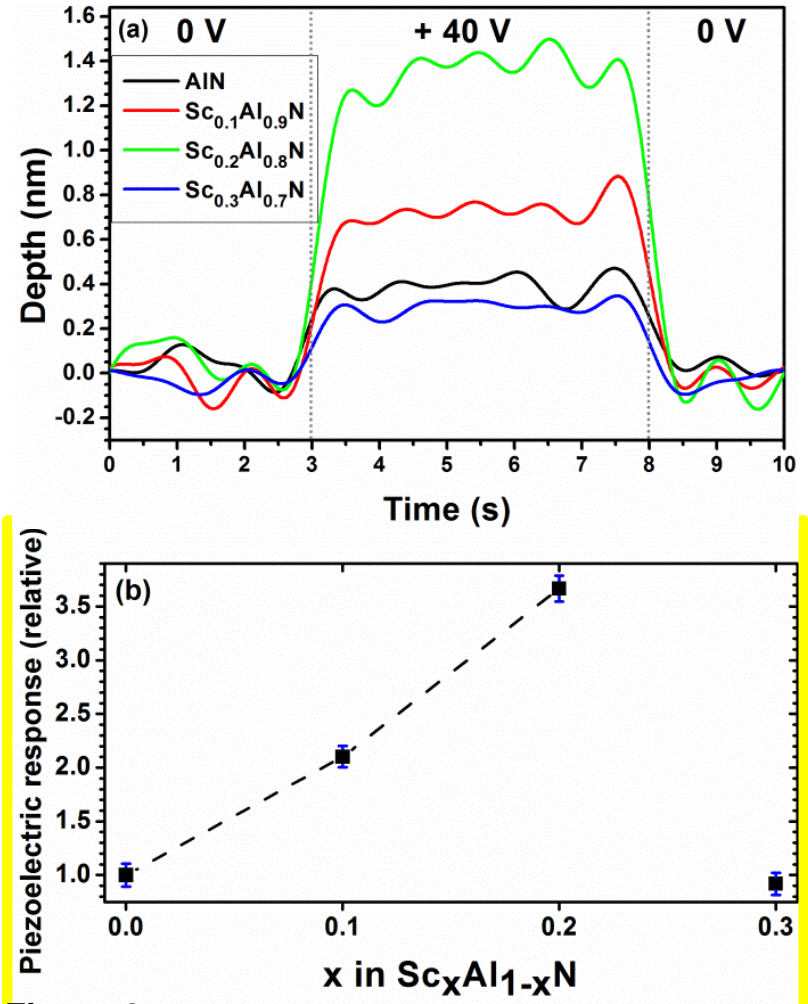

Figure 8 (a) Surface displacement in AlN (black), $\mathrm{Sc}_{0.1} \mathrm{Al}_{0.9} \mathrm{~N}$ (red), $\mathrm{Sc}_{0.2} \mathrm{Al}_{0.8} \mathrm{~N}$ (green), and $\mathrm{Sc}_{0.3} \mathrm{Al}_{0.7} \mathrm{~N}$ (blue), caused by the applied bias voltage $(40 \mathrm{~V})$ during a piezoelectric nanoindentation measurement. (b) Relative piezoelectric response as a function of $\mathrm{Sc}$ concentration in $\mathrm{Sc}_{\mathrm{x}} \mathrm{Al}_{1-\mathrm{x}} \mathrm{N}(0001)$ obtained from the converse measurements. The dashed line is a guide the eyes only.

on the film thickness, however, $\mathrm{d}_{33}$ increases only by about $5 \%$ when thickness is increased from 250 to $500 \mathrm{~nm}$ [23]. The influence of thickness variations in Figure 8 can be considered inside the experimental error, and do not change the observed trends.

The extraction of $d_{33, \mathrm{f}}=\Delta l / \Delta V$ values from such measurements is only be possible in two-dimensional structures, such as piezoelectric nanowires [11], where the elongation $\Delta l$ induced by applied voltage in the out of plane direction is not constrained in-plane, as it is in the continuous film. Therefore, for a qualitative comparison, the averaged surface displacement as a function of Sc concentration was normalized to the reference AlN and is presented in Fig. $8 \mathrm{~b}$ The increase in displacement is close to linear up to $\mathrm{x}=0.2$, and then decreases for the sample with $\mathrm{x}=0.3$. The observed increase in the displacement is more than $360 \%$ which is larger as compared to our previously published DBI and PFM results [3], in which a $180 \%$ increase was observed. It should be noted that the results in Ref. [3] also are qualitative, with AlN as a reference, due to difficulties in obtaining absolute data with both DBI and PFM. The difference between that data and those presented here, based on the converse effect in nanoindentation, might thus be due to uncertainties in any of the three methods as well as different setups used, e.g., different electrode geometries.
For example, the complex electric field around the indenter tip and in the film due to the non-flat anisotropic indenter geometry, as well as $~ 10$ times higher applied voltage may play a role for the converse nanoindentation method. The good qualitative data obtained and the ease of setting up and carrying through the converse piezoelectric measurement with the nanoindenter is very promising. Although it is beyond the scope of this work, a quantification of possible sources of errors should be pursued in order to facilitate absolute data acquisition in the future.

4 Conclusion Wurtzite $\mathrm{Sc}_{\mathrm{x}} \mathrm{Al}_{1-\mathrm{x}} \mathrm{N}(0001)$ thin films $(\mathrm{x}=0,0.1,0.2$, and 0.3$)$ deposited on $\mathrm{TiN}(111) / \mathrm{Al}_{2} \mathrm{O}_{3}$ were grown by reactive magnetron sputter epitaxy at $\mathrm{T}_{\mathrm{s}}=400{ }^{\circ} \mathrm{C}$. The crystal quality of the material decreased with increased Sc concentration as seen in the XRD patterns. PFM mapping showed all films to be homogeneous with respect to the piezoelectric phase. Hardness and reduced elastic modulus $\mathrm{E}_{\mathrm{r}}$ obtained from the nanoindentation experiments decreased with the addition of Sc from $17 \mathrm{GPa}$ in $\mathrm{AlN}$ to $11 \mathrm{GPa}$ in $\mathrm{Sc}_{0.3} \mathrm{Al}_{0.7} \mathrm{~N}$, and $265 \mathrm{GPa}$ down to $224 \mathrm{GPa}$, respectively, and corroborate recent theoretical predictions of $\mathrm{Sc}_{\mathrm{x}} \mathrm{Al}_{1-\mathrm{x}} \mathrm{N}$ elastic constants. The same nanoindentation set up with a conductive boron doped Berkovich tip was used for piezoelectric characterization of the films. Samples with $x=0.3$ showed a diminished piezoelectric response both in the direct and converse measurement mode, in agreement with our previously published work. The direct piezoelectric effect was induced by applying $0.1-11 \mathrm{mN}$ load to generate voltage up to $0.059 \mathrm{~V}$ for $\mathrm{x}=0.2$. Bowing observed in the generated voltage response during the loading/unloading of the tip could be explained by the displacement (penetration depth) differences due to the diverse mechanical properties of the films, and the nonlinear behavior typical for the plastic deformation during the nanoindentation process. The converse piezoelectric effect was induced by using the $d c$ PNI method at bias voltage of $+40 \mathrm{~V}$. In all samples the piezoelectric response, observed as the surface displacement, was fast and repeatable, and increased with the respect to Sc concentration up to $\mathrm{x}=0.2$.

Acknowledgements We acknowledge the financial support by the Linköping Linnaeus Initiative on Nanoscale Functional Materials (LiLiNFM) provided by the Swedish Research Council (VR) under grant No.349-2008-6582. We would also like to acknowledge the contribution by Dr. Gunilla Wingqvist both in experimental work and the discussions. L.H. and E.B. also acknowledge the Swedish Government Strategic Research Area in Materials Science on Functional Materials at Linköping University (Faculty Grant SFO-Mat-LiU \#2009-00971), J.B. acknowledges Linköping University for providing financial support through a personal "Professor's Contract".

\section{References}

[1] M.A. Dubois, P. Muralt, Appl.Phys.Lett. 74, 3032 (1999) 
[2] M. Akiyama, T. Kamohara, K. Kano, A. Teshigahara, Y. Takeuchi, N. Kawahara, Adv Mater 21, 593 (2009)

[3] A. Zukauskaite, G. Wingqvist, J. Palisaitis, J. Jensen, P. O. A Persson, R. Matloub, P. Muralt, Y. Kim, J. Birch, L. Hultman, J.Appl.Phys. 111, 093527 (2012)

[4] R. Matloub, M. Hadad, A. Mazzalai, N. Chidambaram, G. Moulard, C. S. Sandu, T. . Metzger, P. Muralt, Appl.Phys.Lett. 102, 152903 (2013)

[5] F. Tasnádi, B. Alling, C. Höglund, G. Wingqvist, J. Birch, L. Hultman, I. A. Abrikosov, Phys.Rev.Lett. 104, 137601 (2010)

[6] C. Höglund, J. Birch, B. Alling, J. Bareño, Z. Czigány, P. O. A Persson, G. Wingqvist, A. Zukauskaite, L. Hultman, J.Appl.Phys. 107, 123515 (2010)

[7] A. Andrei, K. Krupa, M. Jozwik, P. Delobelle, L. Hirsinger, C. Gorecki, L. Nieradko, C. Meunier, 141, 565 (2008)

[8] V Cimalla and J Pezoldt and,O.Ambacher, J.Phys.D 40, 6386 (2007)

[9] A.B. Mann, D. Heerden, J. B. Pethica, P. Bowes, T. P. Weihs, Philos.Mag.A 82, 1921 (2002)

[10] A. Rar, G. M. Pharr, W. C. Oliver, E. Karapetian, S. V. Kalinin, J.Mater.Res. 21, 552 (2006)

[11] E. Broitman, M. Y. Soomro, J. Lu, M. Willander, L. Hultman, Phys.Chem.Chem.Phys. 15, 11113 (2013)

[12] M. Bhaskaran, S. Sriram, S. Ruffell, A. Mitchell, Adv. Funct. Mater. 21, 2251 (2011)

[13] G. Wingqvist, F. Tasnádi, A. Zukauskaite, J. Birch, H. Arwin, L. Hultman, Appl.Phys.Lett. 97, 112902 (2010)

[14] M. Akiyama, K. Kano, A. Teshigahara, Appl.Phys.Lett. 95, 162107 (2009)

[15] V. Koval, M. J. Reece, A. J. Bushby, J.Appl.Phys. 97, 074301 (2005)

[16] S. Zhang, W. Y. Fu, D. Holec, C. J. Humphreys, M. A. Moram, J.Appl.Phys. 114, 243516 (2013)

[17] S. Zhang, D. Holec, W. Y. Fu, C. J. Humphreys, M. A. Moram, J.Appl.Phys. 114, 133510 (2013)

[18] J.C. Phillips, Bonds and bands in semiconductors, Academic, New York, 1973.

[19] M. Akiyama, K. Umeda, A. Honda, T. Nagase, Appl.Phys.Lett. 102, (2013)

[20] I.N. Sneddon, Int.J.Eng.Sci. 3, 47 (1965)

[21] W.C. Oliver, G. M. Pharr, J.Mater.Res. 7, 1564 (1992)

[22] S. Sridhar, A. E. Giannakopoulos, S. Suresh, J.Appl.Phys. 87, 8451 (2000)

[23] F. Martin, P. Muralt, M. A. Dubois, A. Pezous, J.Vac.Sci.Technol.A Vac.Surf.Films 22, 361 (2004) 